\title{
Study of Insulin Resistance in Type 2 Diabetes Mallitus by Homa-IR Score
}

\author{
Purohit $\mathrm{A}^{\mathbf{1}}$, Tiwari $\mathrm{V}^{\mathbf{2}}$ \\ ${ }^{1}$ Dr Ashish Purohit, Assistant professor, Department of Medicine, LN Medical college, Bhopal, ${ }^{2}$ Dr Varsha Tiwari, Senior \\ resident, Department of pediatrics, LN Medical college, Bhopal, MP, India
}

Address for Correspondence: Dr. Varsha Tiwari, Email: dr.varshatiwari021@gmail.com

\begin{abstract}
Introduction: Insulin resistance precedes and strongly predicts the development of type 2 diabetes mellitus, estimation of insulin resistance was helpful in detection of early complications and selecting the treatment options, hence the present study was planned. HOMA estimated insulin resistance is an independent predictor of cardiovascular disease in type-2 diabetic subjects Materials and Methods: A case control study was carried out in the Department of Medicine comprising 50 newly diagnosed type 2 diabetes mellitus patients and 50 healthy controls. The HOMA IR method was used in the present study for estimation of insulin resistance as it is simple and appropriate. Results: median value of fasting plasma insulin in cases was $7.45 \mu \mathrm{U} / \mathrm{ml}$ with mean $10.53 \pm 9.42 \mu \mathrm{U} / \mathrm{ml}$ while in control was 7.19 with mean $7.43 \pm$ $2.26 \mu \mathrm{U} / \mathrm{ml}$ ( $\mathrm{p}$ value 0.025856 ) and of fasting plasma glucose was $146 \mathrm{mg} / \mathrm{dl}$ with mean $164.12+54.43 \mathrm{mg} / \mathrm{dl}$ and controls had median 112 with mean $110.6+7.07 \mathrm{mg} / \mathrm{dl}$ ( $\mathrm{p}$ value 0.000000 ). The median value of HOMA IR score is 2.91 in cases with mean value of $4.15 \pm 3.56$ and controls of 1.97 , mean $2.03+0.64$ ( $\mathrm{p}$ value .000072 ). The most prevailing complications were retinopathy $26 \%(13, \mathrm{p}<0.01)$ and neuropathy $26 \%(13, \mathrm{P}<0.01)$. Conclusion: HOMA-IR score in present study was higher, it indicates that IR was higher in Patient of T2 DM in Gwalior Chambal zone as compared to other countries and high score is associated with increase risk of diabetic retinopathy, neuropathy, nepropathy, CAD, Peripheral vascular disease.
\end{abstract}

Keywords: HOMA-IR, insulin resistance, type 2 diabetes, nephropathy, neuropathy

\section{Introduction}

Type-2 diabetes mellitus is a heterogeneous disorder characterized by chronic hyperglycemia due to dynamic interactions between varying defects of insulin secretion and insulin resistance. Either of these defects may be the predominant feature in a particular case [1]. 29.1 million people or $9.3 \%$ of US populations have diabetics in which diagnosed is 21.0 million and undiagnosed is 8.1 million people [2]. In adults type $2 \mathrm{DM}$ accounts for about $90-95 \%$ of all diagnosed cases of diabetes.

It usually begins with insulin resistance, a disorder in which the cells primarily with in the muscles, liver, and fat tissue do not use insulin properly [2]. Type 2 diabetics have achieved pandemic proportions and it arises because insulin production is inadequate relation to demand of the body [3]. The hemostasis model assessment- estimated insulin resistance (HOMA-IR)

Manuscript received: $4^{\text {th }}$ Aug 2013

Reviewed: $16^{\text {th }}$ Dec Aug

Author Corrected; $29^{\text {th }}$ Aug 2013

Accepted for Publication: $25^{\text {th }}$ Sep 2014 developed by Matthews et al has widely used for the estimation of insulin resistance in the research [4]. Martins et al [5] established that insulin resistance precedes and strongly predicts the development of type 2 diabetes mellitus among whites in the United States.

There is paucity of such studies in India. At present there is no exact cut off value of insulin resistance by HOMA in various studies among Indians. In the absence of local reference data for HOMA-IR score, we studied the insulin resistance in 50 patients of type- 2 diabetes mellitus and normal healthy controls, to find out the insulin resistance value in type- 2 diabetes mellitus patients and controls in Gwalior Region.

Thus, estimation of insulin resistance was helpful in detection of early complications and selecting the treatment options. Hence the present study was planned. 


\section{Material and Methods}

The present study was a prospective case control study conducted in the Department of Medicine, G.R. Medical College and J.A. Group of Hospitals, Gwalior. Fifty newly diagnosed type 2 diabetes mellitus patients and 50 healthy controls were studied.

Inclusion criteria: American Diabetes Association criteria have been used for selecting the newly diagnosed type-2 diabetes mellitus patients [6].

Exclusion criteria: Patients receiving drugs that alter the insulin sensitivity

Oral hypoglycemic agents (Insulin, $\beta$ agonist, Prazosin, Diuretics, Steroids, OCP's), Condition associated with insulin resistance (PCOD, Thyrotoxicosis, Congestive cardiac failure, Chronic renal failure, Cirrhosis, Pregnancy), Hypertension (JNC - 7 stage I hypertension and stage II hypertension).

The volunteer study subjects, who satisfied the inclusion and exclusion criteria, were educated regarding the study, its aims ad objectives. If they were willing to participate in the study, an informed consent was obtained and the subject taken into the study.

Controls: 50 healthy age and sex matched volunteers who had no personal or family history of diabetes mellitus, hypertension were recruited to serve as controls. Exclusion criteria were clinical evidence of any illness, personal or family history of Diabetes Mellitus, hypertension, current use of any form of medication.

Collection of data: All patients and controls were subjected to detailed history and physical examination and investigations. Information on age, sex and anthropometrics waist circumference, waist hip ratio, height, weight, BMI [wt. $\left.(\mathrm{kg}) / \mathrm{ht}\left(\mathrm{mtr}^{2}\right)\right]$ and ABI (was calculated using mercury sphygmomanometer in both case and control) measures were obtained from all cases and control subjects.

Patients were subjected to fundus examination to find out any diabetic retinal abnormalities.

Fasting (overnight $8 \mathrm{hrs}$ ) and postprandial (2 hrs) venous plasma glucose was determined by glucose oxidase method using glucose auto analyzer. Concentrations of total cholesterol, triglyceride HDL, LDL and cholesterol were determined by enzymatic kinetic method using an auto analyzer. Renal function test viz. blood urea \& serum creatinine were done. Urine routine $\&$ microscopy and urine for microalbumin were also determined.

The serum plasma was stored at $20^{\circ} \mathrm{C}$ until assayed. Corresponding specific insulin concentration was determined by radioimmunoassay (RIA) using a human specific antibody RIA kit ECG was done..

\section{Calculation of insulin resistance by HOMA}

The HOMA method developed in 1985 by Matthews and co-workers was used in this study as it is simple and appropriate to developing countries where dynamic studies like the euglycemic glucose clamp technique [7], though the gold standard may not be feasible due to the degree of sophistication and cost of equipment necessary. Recently resistance in diabetic patients has been the focus of much attention [7,8,9,]. A significant correlation has been reported between the insulin resistance index calculated by HOMA and the hyperinsulinemic-euglycemic clamp (clamp IR ) [7,10].

HOMA-IR was calculated using formula: HOMA IR) =

Fasting plasma glucose (mg/dl)

$\longrightarrow$ Fasting plasma insulin

22.5

The figure 22.5 in equation brings the insulin resistance values to one (Insulin sensitivity of 100\%) of normal subject.

\section{Statistical Analysis}

Statistical analysis was done by calculation of range, median, mean, standard deviation, percentage, odds ratio, chi square test and $\mathrm{p}$ value. The statistical software SPSS 10.0 was used for the analysis of the data and Microsoft word and excel have been used to generate graphs, tables etc. 


\section{Results}

Table No 1: Age wise distribution of cases

\begin{tabular}{|l|l|l|}
\hline Age (in years) & No. of Cases & $\%$ \\
\hline $31-40$ & 09 & $18 \%$ \\
\hline $41-50$ & 18 & $36 \%$ \\
\hline $51-60$ & 20 & $40 \%$ \\
\hline$>61$ & 03 & $06 \%$ \\
\hline Total & $\mathbf{5 0}$ & $\mathbf{1 0 0}$ \\
\hline
\end{tabular}

In the present study, patients were selected from 30 years to 70 years of age, majority of patients being in 50-60 years age group (40\%). The average mean age for the studied cases was $49.98 \pm 8.32$ year $\&$ mean age of controls was $49.98 \pm 8.32$ years.

Table No 2: Insulin Resistance by HOMA-IR Score of cases \& controls

\begin{tabular}{|c|l|l|l|}
\hline Character & Cases & Controls & P-value \\
\hline FPI (microunit/ml) & $0.92-48.47$ & $3.9-15.51$ & 0.025856 \\
Range & 7.45 & 7.19 & \\
Median & $10.53 \pm 9.42$ & $7.43 \pm 2.26$ & \\
Mean \pm SD & $96-371$ & $90-119$ & 0.000000 \\
\hline FPG (mg/dl) & 146 & 112 & \\
Range & $164.12 \pm 54.43$ & $110.6 \pm 7.07$ & \\
Median & $0.22-18.77$ & 1.97 & \\
Mean \pm SD & 2.91 & $2.03 \pm 0.64$ & \\
\hline HOMA-IR Score & $4.15 \pm 3.56$ & & \\
Range & Median & & 1.000072 \\
Mean \pm SD & & & \\
\hline
\end{tabular}

The above table shows the median value of fasting plasma insulin in cases was $7.45 \mu \mathrm{U} / \mathrm{ml}$ with mean $10.53+9.42 \mu \mathrm{U} / \mathrm{ml}$ while median value of fasting plasma in control was 7.19 with mean $7.43+2.26 \mu \mathrm{U} / \mathrm{ml}$ which is statistically significant $(\mathrm{p}$ value 0.025856$)$.

The median value of fasting plasma glucose was $146 \mathrm{mg} . / \mathrm{dl}$ with mean $164.12+54.43 \mathrm{mg} / \mathrm{dl}$ and controls had median 112 with mean $110.6+7.07 \mathrm{mg} / \mathrm{dl}$ which is statistically highly significant (p value 0.000000 ).

Mean value of HOMA-IR was significantly high in cases as compared to controls. 
Table No 3: Co-relation of Complications on the basis of HOMA-IR

\begin{tabular}{|c|c|c|c|}
\hline Complications & $\begin{array}{l}\text { HOMA-IR } \\
\leq 3.31\end{array}$ & $\begin{array}{l}\text { HOMA-IR } \\
>3.31\end{array}$ & P-Value \\
\hline $\begin{array}{l}\text { Retinopathy } \\
\text { Mean } \pm \text { SD } \\
(n=\text { No. of cases })\end{array}$ & $\begin{array}{l}1.93 \pm 0.67 \\
(n=6)\end{array}$ & $\begin{array}{l}9.3 \pm 5.12 \\
(n=7)\end{array}$ & 0.0051 \\
\hline $\begin{array}{l}\text { Nephropathy } \\
\text { Mean } \pm \text { SD } \\
(n=\text { No. of cases })\end{array}$ & $\begin{array}{l}1.77 \pm 0.82 \\
(n=6)\end{array}$ & $\begin{array}{l}7.18 \pm 3.29 \\
(n=5)\end{array}$ & 0.00349 \\
\hline $\begin{array}{l}\text { Neuropathy } \\
\text { Mean } \pm \text { SD } \\
\text { ( } n=\text { No. of cases) }\end{array}$ & $\begin{array}{l}1.8 \pm 0.69 \\
(n=5)\end{array}$ & $\begin{array}{l}5.64 \pm 2.1 \\
(n=8)\end{array}$ & 0.002467 \\
\hline $\begin{array}{l}\text { CAD } \\
\text { Mean } \pm \text { SD } \\
(n=\text { No. of cases })\end{array}$ & $\begin{array}{l}2.06 \pm 1.04 \\
(n=2)\end{array}$ & $\begin{array}{l}5.76 \pm 0.8 \\
(n=3)\end{array}$ & 0.01 \\
\hline $\begin{array}{l}\text { Risk of PVD } \\
\text { Mean } \pm \text { SD } \\
\text { (n= No. of cases) }\end{array}$ & $\begin{array}{l}1.74 \pm 0.27 \\
(n=2)\end{array}$ & $\begin{array}{l}5.68 \pm 0.1 \\
(n=4)\end{array}$ & 0.000009 \\
\hline
\end{tabular}

All complications were significantly higher in patients with HOMA IR $>3.31$.In the present study, most common complications in type $2 \mathrm{DM}$ were retinopathy \& neuropathy (26\% each) followed by nephropathy in $22 \%$ cases, CAD in $10 \%$ cases and risk of PVD in $12 \%$.

Table No 4: Relationship between Albumin/Creatinine Ratio \& HOMA-IR

\begin{tabular}{|c|c|c|c|}
\hline \multirow{2}{*}{ Alb./Cr. Ratio $(\mathrm{mg} / \mathrm{g})$} & \multicolumn{2}{|l|}{ HOMA-IR } & \multirow{2}{*}{ P-value } \\
\hline & $\leq 3.31$ & $>3.31$ & \\
\hline $\begin{array}{l}\text { ND }-<\mathbf{3 0} \\
\text { Mean } \pm \text { SD } \\
(n=\text { No. of cases })\end{array}$ & $\begin{array}{l}1.97 \pm 0.78 \\
(n=22)\end{array}$ & $\begin{array}{l}6.95 \pm 3.92 \\
(n=17)\end{array}$ & 0.000001 \\
\hline $\begin{array}{l}\text { 30-300 } \\
\text { Mean } \pm \text { SD } \\
(n=\text { No. of cases })\end{array}$ & $\begin{array}{l}1.77 \pm 0.82 \\
(n=6)\end{array}$ & $\begin{array}{l}6.02 \pm 2.55 \\
(n=4)\end{array}$ & 0.004571 \\
\hline $\begin{array}{l}>\mathbf{3 0 0} \\
\text { Mean } \pm \mathrm{SD} \\
(\mathrm{n}=\text { No. of cases })\end{array}$ & - & $\begin{array}{l}11.48 \pm \\
(n=1)\end{array}$ & - \\
\hline
\end{tabular}

Above table shows that most of the patients had albumin creatinine ratio $<30 \mathrm{mg} / \mathrm{g}$. Out of 39 patients, 17 patients had HOMA IR $>3.31 .11$ patients had albumin creatinine ratio $>30 \mathrm{mg} / \mathrm{g}$, of which 5 patients had HOMA IR $>3.31$.

(In present study, 39 patients had normal albumin/creatinine ratio $(<30 \mathrm{mg} / \mathrm{dl})$ while 11 patients showed albumin/creatinine ratio $>30 \mathrm{mg} / \mathrm{dl}$. Out of 39 patients having normal albumin/creatinine ratio, 17 patients had HOMA-IR $>3.31$ while out of 11 patients having disturbed albumin/creatinine ratio, 5 patients had insulin resistance.) 


\section{Discussion}

The HOMA method developed by Mathew's \& co-workers (1985)[11] was used in the present study for estimation of Insulin resistance as it is simple and appropriate. The HOMA method has been re-validated as a reliable method to asses insulin resistance in clinical practice as the HOMA IR score is shown to closely mirror the insulin resistance obtained by euglycemic clamp technique in assesment of insulin resistance (BONORA E et-al 2000)[7]. At present there is no exact cut off value of HOMA available in India. The present study was undertaken to find out insulin resistance value in $\mathrm{T}_{2} \mathrm{DM}$ patients and age \& sex matched healthy controls.

\section{Complications}

In the present study, most common complications in type $2 \mathrm{DM}$ were retinopathy \& neuropathy ( $26 \%$ each) followed by nephropathy in $22 \%$ cases, CAD in $10 \%$ cases and risk of PVD in $12 \%$.

\section{Fasting plasma glucose, Fasting plasma Insulin and Insulin resistance}

Mean value of fasting plasma insulin in cases was found to be $10.53 \pm 9.42 \mu \mathrm{U} / \mathrm{ml}$ while in controls $7.43 \pm 2.26 \mu \mathrm{U} / \mathrm{ml}$ with $\mathrm{p}$ value (0.025) which is statistically significant as shown in table no.12. Adamu G Bakari et al. (2005)[12] study found mean FPI $4.20 \pm 1.78 \mu \mathrm{U} / \mathrm{ml}$ in 40 T2 DM patients, Vijay Vishwanathan et al (2010)[13] found mean FPI 46.1 $\pm 2.5 \mu \mathrm{U} / \mathrm{ml}$ in controls in their study.

In the present study, mean FPI in cases was found to be higher than other studies i.e. may be marker of Insulin resistance.

Mean Fasting plasma Glucose in cases was $164.12 \pm 54.43 \mathrm{mg} / \mathrm{dl}$ while in controls it was $110.6 \pm 7.07 \mathrm{mg} / \mathrm{dl}$ with P value 0.000 and this difference is statistically significant.

Mean HOMA IR Score in studied cases was $4.15 \pm 3.56$ \& mean HOMA IR score in controls was $2.03 \pm 0.64$ with P value 0.000072 which was statistically highly significant. It means that Insulin resistance was found in type $2 \mathrm{DM}$ patients.

HOMA IR in cases found to be mean 4.15 \pm 3.56 . Adamu $G$ et al (2005)[12] found mean HOMA-IR 1.73 in diabetic patients, Akira et al (2001)[14] found mean HOMA IR 2.04 1.56 in 55 type 2 DM patients. Bonora et al (2000)[7] found mean HOMA-IR of 2.06 \pm 0.14 in non diabetic normal population. Enzo Bonora et al (2007)[15] reported HOMA-IR of 2.5 in normal subjects. Hui- Qi Qu, et al (2011)[16] study showed that the best cut off of HOMA-IR for identifying those with insulin resistance is 3.80. HOMA-IR score in present study was higher than previous studies it indicates that IR was higher in Patient of T2 DM in Gwalior Chambal zone as compared to other countries.

It is interesting that equation given by Mathew \& co-workers [11] in 1985 shows that HOMA-IR 1 is equivalent to insulin sensitivity of $100 \%$ but in present study it was found that the mean value of HOMA IR score in cases was $4.15 \pm 3.56$ while in healthy controls it was $2.03 \pm 0.64$ so normal cut off value for HOMA-IR in healthy controls is difficult to specify.

Mathew \& co-workers (1985)[11] said that normal value of HOMA-IR in healthy controls should be 1 but the present study shows that the mean value of HOMA-IR in healthy control was $2.03 \&$ by adding two standard deviation the normal cut off value should be $2.03 \pm 2 \times 0.64$ equal to 3.31 . It indicates that the normal cut off value of HOMA-IR in healthy persons in present study was 3.31. Previously HOMA-IR was calculated in healthy controls in various studies which are summarized in table from given below.

Table 5: showing comparison between various studies

\begin{tabular}{|l|l|l|l|l|}
\hline Study & Age (yrs) & FPG & FPI & HOMA score \\
\hline Adamu G Bakari 2005 & $49.4 \pm 9.7$ & $\begin{array}{l}9.77 \pm 4.03 \\
(\mathrm{mmol} / \mathrm{L})\end{array}$ & $\begin{array}{l}4.2 \\
1.78(\mu \mathrm{U} / \mathrm{ml})\end{array}$ & $1.73 \pm 1.4-7.6)$ \\
\hline Enzo Bonora et al 2007 & $57.2 \pm 11.2$ & $5.5(\mathrm{mmol} / \mathrm{L})$ & $75(\mathrm{pmol} / \mathrm{L})$ & $2.5 \pm 1.7-3.9$ \\
\hline Angelica Sink et al 2007 & - & - & - & Considered HOMA <2 is normal \\
\hline $\begin{array}{l}\text { Srinivas et al Martha } \\
2008\end{array}$ & $\begin{array}{l}75.58 \quad \pm \\
8.56\end{array}$ & $\begin{array}{l}76.83 \pm 14.49 \\
(\mathrm{mg} / \mathrm{m})\end{array}$ & $\begin{array}{l}4.39 \\
2.68(\mu \mathrm{U} / \mathrm{ml})\end{array}$ & $0.89 \pm 0.63$ \\
\hline Our study & $49.98 \pm 8.32$ & $\begin{array}{l}110.6 \pm 7.07 \\
(\mathrm{mg} / \mathrm{dl})\end{array}$ & $\begin{array}{l}7.43 \pm 2.26 \\
(\mu \mathrm{U} / \mathrm{ml})\end{array}$ & $2.03 \pm 0.64$ \\
\hline
\end{tabular}


Research Article

Total 13 patients had diabetic retinopathy in studied group. Out of 13 patients, 7 patients of diabetic retinopathy had HOMA-IR score more than 3.31 while 6 patients had HOMA-IR less than cut off value with $p$ value of 0.0051 , so higher insulin resistance was statistically significant factor in the development of diabetic retinopathy.

In the present study total 11 patients had diabetic nephropathy, of which 5 patients with diabetic nephropathy had HOMAIR $>3.31$ while 6 patients of diabetic nephropathy have HOMA-IR $\leq 3.31$ with P Value $(0.00349)$ which was statistically significant factor. Thus, insulin resistance is associated with development of diabetic nephropathy.

Vijay Vishwnathan et al (2010)[13] also found high Insulin resistance in T2 DM patients associated with diabetic neuropathy they found that mean HOMA-IR significantly increases with progression of renal disease.

In the present study total 5 patients had CAD, of which 3 patients had HOMA-IR $>3.31$ while 2 patients had HOMA-IR $\leq 3.31$ with $\mathrm{p}$ Value (0.01) which statistically significant thus insulin resistance was a significant factor in development of CAD.

In the present study 13 patients had neuropathy, of which 8 patients had HOMA-IR $>3.31$ while 5 patients had HOMA$\mathrm{IR} \leq 3.31$ with $\mathrm{p}$ value 0.002467 which is statistically significant factor in development of neuropathy.

In the present study total 6 patients had PVD; of which 4 patients had HOMA-IR score more than $3.31 \& 2$ patients had HOMA $\leq 3.31$ which is statistically significant. Thus insulin resistance was significant factor in development of PVD.

\section{Diabetic Nephropathy}

Mean blood urea in cases was $31.96 \pm 10.84 \mathrm{mg} / \mathrm{dl}$ and in controls $29.76 \pm 6.56 \mathrm{mg} / \mathrm{dl}$ mean serum creatinine value was $0.89 \pm 0.17 \mathrm{mg} / \mathrm{dl}$ in cases and $0.87 \pm 0.113 \mathrm{mg} / \mathrm{dl}$ in controls ( $\mathrm{p}$ value 0.49 ).

Albumin creatinine ratio is important indicator of nephropathy. Vijay Vishwanathan et al (2010)[13] studied insulin resistance in different stages of diabetic renal dysfunction.

They found that insulin resistance increases with worsening of renal function.

In present study, 39 patients had normal albumin/creatinine ratio $(<30 \mathrm{mg} / \mathrm{dl})$ while 11 patients showed albumin/creatinine ratio $>30 \mathrm{mg} / \mathrm{dl}$.

Out of 39 patients having normal albumin/creatinine ratio, 17 patients had HOMA-IR $>3.31$ while out of 11 patients having disturbed albumin/creatinine ratio, 5 patients had insulin resistance.

\section{Conclusions}

Mean value of HOMA-IR was significantly high in cases as compared to controls. In present study the normal cut off value for HOMA IR was 3.31. 44\% type 2 DM patients had insulin resistance (HOMA IR $>3.31$ ) while $4 \%$ controls had insulin resistance (HOMA IR>3.31).

In day to day practice clinicians must think about insulin resistance in diabetic patients. As insulin resistance is an independent risk factor in diabetic patients in addition to all well established risk factors i.e. CAD, Hypertension, and Obesity.

It should be measured in all the diabetic patients because it is cheap and easily measurable from FPI and fasting blood sugar level.

Its measurement will help to prevent the development of various complications of diabetes at early stages.

Funding: Nil

Conflict of interest: None, Permission from IRB: Yes 
Research Article

\section{References}

1. World Health Organization. Definition, Diagnosis and classification of diabetes mellitus and its complications. Report of a WHO consultation, WHO;Geneva,1999. Available from Whqlibdoc.who. int/hq / 1999/ who_ncd_ncs_99.2.pdf cited on $4^{\text {th }}$ Aug 2014.

2. National diabetes statistics report, 2014 - centers for disease control. http://www.cdc.gov/diabetes/ pubs/ statsreport14/national-diabetes-report-web.pdf cited on 4th Aug 2014.

3. Diapedia, the living text book of diabetics. www.diapedia.org/type-1-diabetes-mellitus/

environmental-factors Aug 13, 2014 cited on aug 2014.

4. Nolan JJ, Færch K. Estimating insulin sensitivity and beta cell function: perspectives from the modern pandemics of obesity and type 2 diabetes. Diabetologia. 2012 Nov; 55(11):2863-7. Epub 2012 Aug 22.

5. Martin BC1, Warram JH, Krolewski AS, Bergman RN, Soeldner JS, Kahn CR. Role of glucose and insulin resistance in the development of type 2 diabetes mellitus: results of a 25 year follow up study. Lancet. 1992 Oct 17;340(8825):925-9.

6. American Diabetes Association. Standards of Medical Care in Diabetes - 2008. Diabetes Care. 2008;31 (Supp1 1):S13-S54.

7. Bonora E, Saggaini F, Targher G, et al. Homeostasis Model Assessment closely mirrows the glucose clamp technique in the assessment of insulin sensitivity. Diabetes Care 2000;23:23-25.

8.Defronzo RA Tobin JD, Andres R . Glucose clamp technique: a method of quantifying insulin secretion and resistance.[internet] available from : Am J Physiol. 1979 Sep;237(3):E214-23

9. Emoto M, Nishizawa Y, Maekawa K, Hiura Y, Kanda H, Kawagishi T, Shoji T, Okuno Y, Morii H: Homeostasis model assessment as a clinical index of insulin resistance in type 2 diabetic patients treated with sulfonylureas. Diabetes Care. 1999 May;22(5):818-22.

10. Fukushima M, Taniguchi A, Sakai M, Doi K, Nagasaka S, Tanaka H, Tokuyama K, Nakai Y: Homeostasis model assessment as a clinical index of insulin resistance: comparison with the minimal model analysis (Letter). Diabetes Care 22:1911, 1999.

11. Olefsky JM., Kollerman OG, Mechanisms of Insulin resistance in obesity and NIDDM.Amer. JJvted 1981,Am J Med Jan;70(1):151-68.

12. Matthews, DR, Hosker, JP; Rudenski, AS, Naylor, BA, Treacher, DF, Turner, RC. Homeostasis model assessment : insulin resistance and the cell function from fasting plasma glucose and insulin concentration in man. Diabetologia. 1985;28:412-419.

13. Nigerians. Adamu G Bakari and Geoffrey C Onyemelukwe: Insulin resistance in type 2 diabetic. Int J Diabetes \& Metabolism (2005) 13: 24-27.

14. Vijay Viswanathan, priyanka TIlak, Rafi Meerza, Satyavani Kumpatla: Insulin resistance at different stages of diabetic kidney disease in India. Vol.58, Oct. 2010.

15. Akira Katsuki, MD, Yasuhiro Sumida, MD Rika Araki Sasaki, MD et al: Homeostasis Model Assessment is a reliable indicator of insulin resistance during follow up of patients with type 2 diabetes, Diabetes care 24:362-365, 2001

16. Enzo Bonora, MD, PHd Stefan Kiechi, Johann Willett et al Insulin resistance as esimtaed by homesotasis model assessment predicts incident symptomatic cardiovascular disease in Caucasian subjects from the general population: Diabetes care: vol. 30, number 2 Feb. 2007

17. Hui- Qi Qu, Quan Li et al . Definition of insulin Resistance using HOMA-IR for americans of Mexican descent using machine learning.june 14, 2011. Available from: http://www.plosone.org cited on $4^{\text {th }}$ Aug 2014.

\section{How to cite this article?}

Purohit V, Tiwari V. Study of Insulin Resistance in Type 2 Diabetes Mallitus by Homa-IR Score. Int J Med Res Rev 2015;3(1):3-9. doi:10.17511/ijmrr.2015.i1.02 